\title{
Spinal Cats on the Treadmill: Changes in Load Pathways
}

\author{
Marie-Pascale Côté, Ariane Ménard, and Jean-Pierre Gossard \\ Centre de Recherche en Sciences Neurologiques, Département de Physiologie, Faculté de Médecine, Université de Montréal, Montréal, Québec, Canada \\ H3C 3J7
}

Treadmill training and clonidine, an $\alpha-2$ noradrenergic agonist, have been shown to improve locomotion after spinal cord injury. We speculate that transmission in load pathways, which are involved in body support during stance, is specifically modified by training. This was evaluated by comparing two groups of spinal cats; one group $(n=11)$ was trained to walk until full-weight-bearing (3- 4 weeks), and the other (shams; $n=7$ ) was not. During an acute experiment, changes in group I pathways, monosynaptic excitation, disynaptic inhibition, and polysynaptic excitation were investigated by measuring the response amplitude in extensor motoneurons before and after clonidine injection. Monosynaptic excitation was not modified by clonidine but was decreased significantly by training. Disynaptic inhibition was significantly decreased by clonidine in both groups, but more significantly in trained cats, and significantly reduced by training after clonidine. Also, clonidine could reverse group IB inhibition into polysynaptic excitation in both groups but more frequently in trained cats. We also investigated whether fictive stepping revealed additional changes. In trained cats, the phase-dependent modulation of all three responses was similar to patterns reported previously, but in shams, modulation of monosynaptic and polysynaptic responses was not. Overall, training appears to decrease monosynaptic excitation and enhance the effects of clonidine in the reduction of disynaptic inhibition and reversal to polysynaptic excitation. Because it is believed that polysynaptic excitatory group I pathways transmit locomotor drive to extensor motoneurons, we suggest that the latter changes would facilitate the recruitment of extensor muscles for recovering weight-bearing during stepping.

Key words: locomotion; weight-bearing; treadmill training; reflex pathways; spinalization; motor control

\section{Introduction}

Treadmill training has been shown to successfully enhance and maximize residual locomotor capacities of spinal cord injured (SCI) patients (Fung et al., 1990; Wernig et al., 1995; Harkema et al., 1997; Harkema, 2001). Previous studies first demonstrated this beneficial effect in adult spinal cats that have a remarkable capacity to recover locomotion (Lovely et al., 1986; Barbeau and Rossignol, 1987; Bélanger et al., 1996; De Leon et al., 1998). Moreover, clonidine, an $\alpha$-2 noradrenergic agonist, improves and accelerates the recovery of stepping early after spinalization in cats (Forssberg and Grillner, 1973; Barbeau and Rossignol, 1991; Chau et al., 1998) and, when combined with treadmill training, improves walking patterns in SCI humans (Fung et al., 1990; Rémy-Néris et al., 1999).

The repeated sensory stimulation provided during treadmill training is the only source of input that the transected spinal cord can use to trigger recovery and underlying plastic changes (De Leon et al., 1999). But which sensory input is most important for recovery? It has been shown in many species, including humans (Prochazka, 1996; Duysens et al., 2000), that sensory feedback from load receptors in the legs has a particularly powerful effect on the activity of the central pattern generator $(\mathrm{CPG})$ for loco-

\footnotetext{
Received May 1, 2002; revised Jan. 15, 2003; accepted Jan. 21, 2003.

This work was supported by the Canadian Institutes of Health Research and the Christopher Reeve Paralysis Foundation. M.-P.C. was supported by the joint Fonds pour la Formation de Chercheurs et I'Aide à la Recherche du Québec and Fonds de la Recherche en Santé du Québec (FCAR-FRSQ). A. M. was supported by the Natural Sciences and Engineering Council of Canada and FCAR-FRSQ. We thank F.-J. Lapointe for assistance in statistical analysis and F. Lebel for technical support.

Correspondence should be addressed to Dr. Jean-Pierre Gossard, Centre de Recherche en Sciences Neurologiques, Département de Physiologie, Faculté de Médecine, Université de Montréal, C.P. 6128, Succ. Centre-ville, Montréal, Québec, Canada H3C 3J7. E-mail: jean-pierre.gossard@umontreal.ca.

Copyright $\odot 2003$ Society for Neuroscience $\quad 0270-6474 / 03 / 232789-08 \$ 15.00 / 0$
}

motion. Of particular interest is the reflex reversal occurring when IB inhibition (negative feedback) in extensors is replaced by excitation (positive feedback), reinforcing weight support during the stance phase of stepping (Gossard et al., 1994; Prochazka, 1996). This reversal is state dependent [i.e., it occurs only when the spinal cord is generating locomotion (Gossard and Hultborn, 1991; Stephens and Yang, 1996) or after injection of L-Dopa (Gossard et al., 1994) or clonidine (McCrea et al., 1995)]. Here, we hypothesize that transmission of group I (IA plus IB) pathways is specifically modified by training to assist extensors during stance. We tested this by comparing two groups of cats transected at T13; one group was trained on a treadmill until "full-weightbearing" (3-4 weeks), and the other was spinalized but not trained. Synaptic transmission was evaluated during an acute experiment using intracellular recordings of motoneurons before and after clonidine injection. We found that treadmill training did induce plastic changes in the transmission of group I pathways from extensors that could be helpful for recovering weightbearing during stance.

\section{Materials and Methods}

All procedures were conducted according to the Guide for Care and Use of Experimental Animals of Canada using protocols approved by the Ethics Committee of Université de Montréal.

Spinalization and locomotor training. Eighteen adult female cats (2.5$4.1 \mathrm{~kg}$ ) were used for this study. After administration of preoperative medication, the cats were anesthetized (isoflurane, 2\%; Abbott Labs, Montreal, Canada) and spinalized at T13 under aseptic conditions. Protocols for spinalization procedures and subsequent postoperative care were analogous to those described previously (Chau et al., 1998). A patch of fentanyl (Duragesic, $25 \mu \mathrm{g}$; Janssen-Ortho, Markham, Canada) was sutured on the back of the cat for continuous and stable delivery of 
analgesic over a $2 \mathrm{~d}$ period. The first group of cats (sham) was only spinalized, whereas the second group (trained) was also trained to walk until they could support the weight of their hindquarters (referred to as full-weight-bearing, as in previous reports), which took $\sim 1$ month (mean, $28 \mathrm{~d}$ ). Training on the treadmill $(0.2-0.4 \mathrm{~m} / \mathrm{sec})$ started $2 \mathrm{~d}$ after surgery and consisted of one to four daily training sessions for periods of $10 \mathrm{~min}$. In early training, hindquarters were sustained by the experimenter to provide weight support, and perineal stimulation was used to induce and maintain locomotion. The animal gradually became able to support its hindquarters, and perineal stimulation was no longer needed. No drugs were used to assist the locomotor training. The training was stopped when the cat was able to walk continuously on the treadmill for $>5$ min while the experimenter assisted only for lateral stability by holding the tail.

Acute experiment. Cats were first anesthetized by inhalation of an oxygenated mixture $(50 \%)$ of nitrous oxide $(50 \%)$ and halothane $(2-3 \%$; MTC Pharmaceuticals, Cambridge, Canada). Cannulas were inserted in the right common carotid artery to monitor blood pressure and in the jugular and cephalic veins for administration of pharmacological agents or fluids. Cats were then decerebrated and curarized (Pavulon, $0.2 \mathrm{mg} /$ kg, 45 min; Sabex, Boucherville, Canada) and artificially ventilated as detailed previously (Ménard et al., 1999; Leblond et al., 2000).

The following muscle nerves from the left hindlimb were dissected free, cut, and mounted on bipolar silver chloride electrodes for recording [electroneurogram (ENG)] and stimulation: posterior biceps-semitendinosus (PBSt), semimembranosus-anterior biceps (SmAB), lateral gastrocnemius-soleus (LGS), medial gastrocnemius (MG), plantaris (Pl), flexor hallucis longus (FHL) and flexor digitorum longus together, tibialis anterior, extensor digitorum longus, and the sciatic nerve (uncut). Quadriceps nerves (Quad) were not cut and were inserted in a polymer-cuff electrode. SmAB and PBSt nerves from the right hindlimb were also mounted for recording and stimulation.

Stimulation, recordings, and analysis. The cord dorsum potential (CDP) was recorded with a silver chloride-ball electrode located near the dorsal root entrance at the L6-L7 border. Stimulation intensity required to just evoke a deflection in the CDP determined the threshold for the most excitable fibers for each nerve $(1 \mathrm{~T})$. Stimulus intensity will be expressed as a multiple of the threshold.

Intracellular potentials evoked by the stimulation of group I afferents of extensors [Pl, LGS, MG, sometimes together (gastrocnemii-soleus, GS), Quad; six pulses (p), 1.4-1.8 T, 200-300 Hz] were recorded in identified motoneurons (Leblond et al., 2000) with glass micropipettes filled with $\mathrm{K}^{+}$-acetate $(2 \mathrm{M})$ and $\mathrm{N}$-(2,6-dimethylphenylcarbamoylmethyl) triethylammonium bromide $(100 \mathrm{~mm}$; Alamone Laboratories, Jerusalem, Israel) to prevent sodium spikes. The duration of the afterhyperpolarization (AHP) was measured in every cell, from the spike onset to the point at which the AHP crosses the baseline (Gustafsson and Pinter, 1984). Stimulation trains of peripheral nerves were given every $0.3,0.4$, or $0.5 \mathrm{sec}$. The amplitude of EPSPs and IPSPs in motoneurons evoked by monosynaptic, disynaptic, and/or polysynaptic pathways was measured (Fig. 1). A "trial" is the averaged response in one motoneuron evoked by the stimulation of a given pathway (an afferent-motoneuron pair). Several trials could be studied from the responses of a given motoneuron. The amplitude of monosynaptic EPSPs was measured at a latency of $1.4 \mathrm{msec}$ (i.e., just before the onset of possible disynaptic components) (McCrea et al., 1995; Gosgnach et al., 2000). A train of stimuli evoked either disynaptic inhibition or polysynaptic excitation depending on the conditions (Gossard et al., 1994). The amplitude of IPSP attributable to IB inhibition was measured at the maximal negative deflection in the intracellular trace in response to the stimulation train, and the amplitude of EPSP resulting from polysynaptic excitation was measured at the maximal positive deflection, as illustrated by dotted lines in Figure 1. McCrea et al. (1995) have shown that polysynaptic excitation is not just masking the IB inhibition, but that the latter completely disappears when there is a reversal. Thus, in our calculation, the finding of an excitation (reversal) was considered a $100 \%$ reduction of inhibitory transmission. Conversely, a cell showing IB inhibition was considered to have zero transmission in excitatory pathways. We also studied the long-lasting motor responses to the stimulation of flexor reflex afferents (FRA) from
(A) Monosynaptic excitation
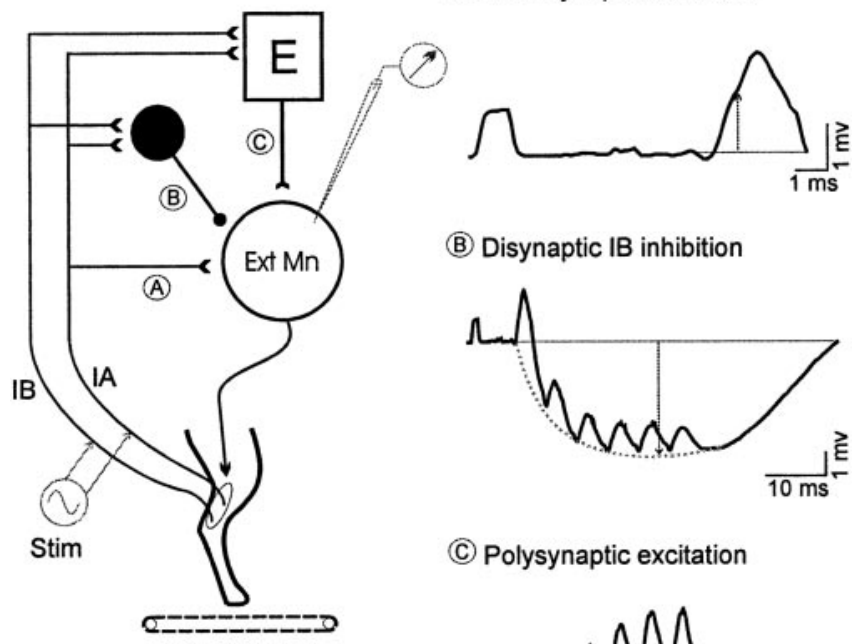

(B) Disynaptic IB inhibition

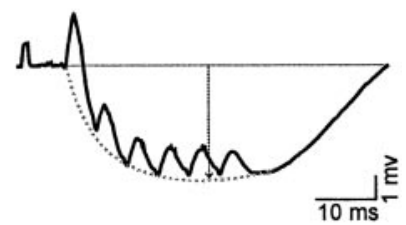

(C) Polysynaptic excitation

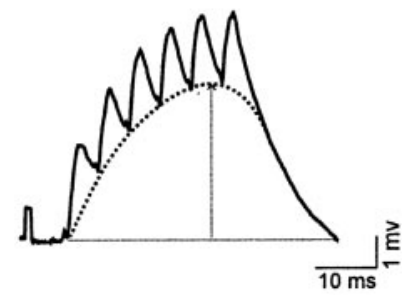

Figure 1. Spinal proprioceptive pathways under study. A schematic representation of three sensory pathways transmitting inputs from muscle group I afferents to extensor motoneurons (ExtMn) is shown to the left: the monosynaptic (stretch reflex) pathway (from group IA afferents originating in muscle spindles of extensors), the disynaptic inhibitory pathway (from group IB afferents of extensors originating in Golgi-tendon organs plus some group IA fibers), and the polysynaptic excitatory pathway (from group IB and IA afferents of extensors). In the acute spinal cat, this latter pathway shares interneurons with the network generating the excitatory locomotor drive in extensors (box E). Sample records of motoneuronal postsynaptic potentials used for measurements are on the right. $a$, The amplitude of monosynaptic EPSPs was measured at a latency of $1.4 \mathrm{msec}$ (rising phase in this example; i.e., just before the onset of possible disynaptic components). $b$, The disynaptic I $B$ inhibition was evoked by a short train of stimuli (6 pulses, $1.4-2.0 \mathrm{~T}, 200-300 \mathrm{~Hz}$ ), and the IPSP amplitude was measured at the maximal negative deflection in the intracellular trace. Note that there were often monosynaptic EPSPs (six positive humps) overriding the inhibitory trough (dotted line). c, Polysynaptic excitation was evoked by a similar short train of stimuli, and the amplitude was measured at the maximal positive deflection (dotted line) underlying monosynaptic EPSPs.

each leg. For this, the PBSt and SmAB nerves of either leg were stimulated together with a train of 50 pulses at $50 \mathrm{~T}$.

All responses were also studied during a period of $2 \mathrm{hr}$ after $500 \mu \mathrm{g} / \mathrm{kg}$ intravenous clonidine injection (Sigma, St. Louis, MO) and during fictive locomotion induced by perineal stimulation. Up to two doses of clonidine were injected in an experiment, and data were recorded for the next $2 \mathrm{hr}$. Once clonidine was injected, there was no return to control conditions, and all subsequent recordings were considered postclonidine data. Bursts of ENG activities were used to divide the step cycle into flexion (corresponding to swing) and extension (corresponding to stance) phases. The locomotor cycle, defined as the period between the onsets of two successive bursts of ENG activity in extensors, was normalized to the duration of the averaged cycle. Postsynaptic potentials evoked during flexion and extension were separated and averaged to study phase-dependent modulation.

Statistical analysis. Results in figures are expressed as means \pm SEM. Statistical analysis was performed to disclose differences between the sham and trained groups, between the averaged responses in all motoneurons obtained before and after clonidine injection, between rest and fictive locomotion (state-dependent changes), and between flexion and extension phases (phase-dependent changes). The KolmogorovSmirnov-Liliefors (KSL) test was used to compare the shape and location of the distribution of responses with a normal distribution. If KSL confirmed that the sample variables did fit a normal distribution, a one-way 


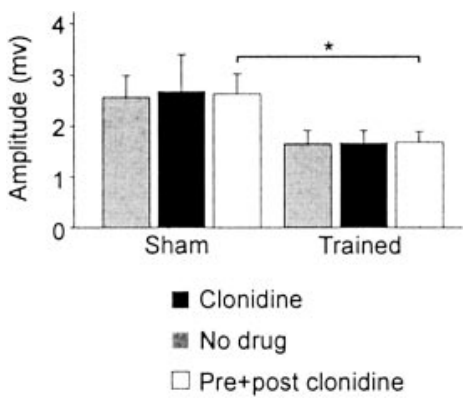

Figure 2. Clonidine did not modify monosynaptic excitation. The mean amplitude of monosynaptic EPSPs (109 trials in 73 cells) evoked by the stimulation of knee and ankle extensor group I afferents (Quad, PI, LGS, MG) was not changed significantly by clonidine injection. If we grouped all values together (preclonidine and postclonidine), there is a significant decrease in the amplitude monosynaptic EPSPs ( ${ }^{*} p<0.05$ ) caused by training. Filled bars, Clonidine; gray bars, no drug; open bars, preclonidine and postclonidine.

ANOVA was performed; if not, the Kruskal-Wallis one-way ANOVA on ranks was used. The $\chi^{2}$ test with the Yates correction factor was used to compare the occurrence of polysynaptic excitation between groups. Significant differences are indicated by asterisks $\left({ }^{*} p<0.05 ;{ }^{* *} p<0.01\right.$; $\left.{ }^{* * *} p<0.001\right)$.

\section{Results}

Changes in the transmission of group I pathways from extensors were monitored by measuring the peak amplitude of EPSPs and IPSPs at specific latencies in several extensor motoneurons of 11 trained (22 LGSs, $18 \mathrm{MGs}, 12 \mathrm{Pls}, 14 \mathrm{FHLs}, 19 \mathrm{SmAB}$ ) and seven nontrained (12 LGSs, 20 MGs, 10 Pls, 9 FHLs, 13 SmAB, 3 Quad) cats. Overall, we measured the responses evoked by 314 afferentmotoneuron pairs (134 in shams, 180 in trained cats) with a mean of 2, 29 pairs (range, 1-5) per motoneuron. Although responses varied between motoneurons, similar trends were observed among shams and trained cats. Data pooled according to motor nuclei or stimulated nerves did not show significant trends. For this reason, and because there is extensive convergence and divergence in the three pathways under study (Jankowska, 1992), we grouped all extensor motoneurons in the different conditions for additional analysis. In the first part, we compared the effects of clonidine in trained and nontrained cats. In the second part, responses were studied during fictive locomotion, which occurs in a curarized cat (i.e., without movement-related sensory feedback or reafference).

\section{Training and clonidine}

The monosynaptic stretch reflex is thought to make a major contribution to the level of EMG activities during stepping (Stein et al., 2000), although this role in humans was questioned previously (Sinkjaer et al., 2000). Clonidine did not affect the amplitude of monosynaptic EPSP significantly (Fig. 2). When preclonidine and postclonidine values were grouped together, it was found that the amplitude of monosynaptic excitation was significantly decreased (by 36\%) by training (Fig. 2). Motoneurons, divided in two groups according to their AHP duration, corresponding approximately to slow $(>50 \mathrm{msec})$ and fast $(20-50$ msec) motor units, were also compared before and after clonidine and between shams and trained cats, but no significant changes were observed.

To evaluate transmission in the IB inhibitory pathways, we measured and compared disynaptic IPSPs in response to a short train of stimuli (appropriate to recruit interneurons) in group I (IA plus IB) (Jankowska and McCrea, 1983; Jankowska, 1992) a

Sham

b

Trained

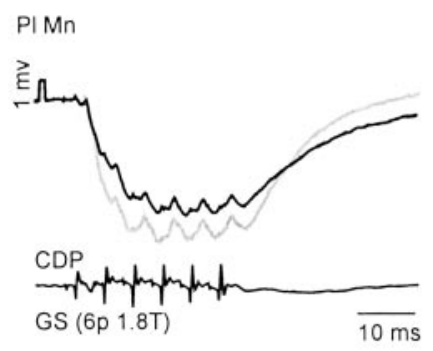

LGS Mn

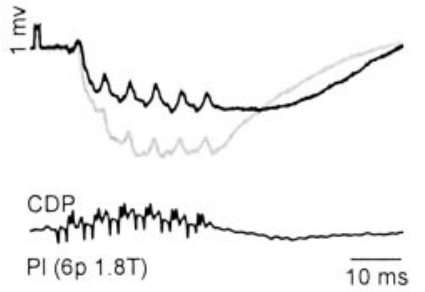

C
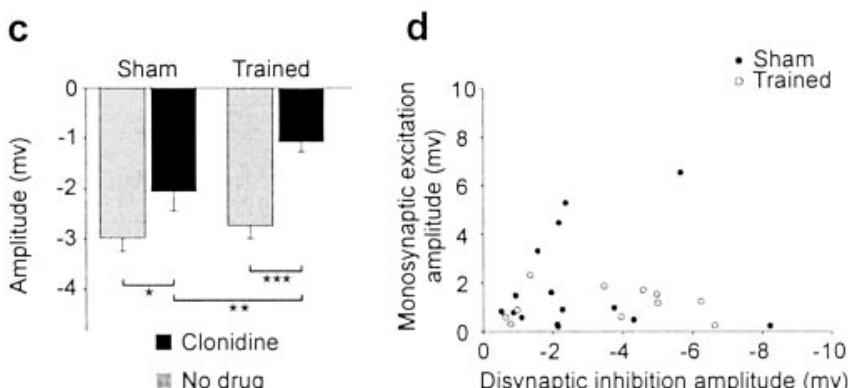

Figure 3. Training plus clonidine injection decreased disynaptic IB inhibition. $a, b$, IPSPS evoked by stimulation of $\mathrm{GS}$ group I afferents $[6 \mathrm{p} 1.8 \mathrm{~T}]$ in a PI motoneuron in a sham $(a)$ and $\mathrm{PI}$ group I afferents ( $6 \mathrm{p} 1.8 \mathrm{~T}$ ) in an LGS motoneuron (similar AHP as the PI cell) in a trained cat $(b)$ before ( gray trace) and after (black trace) clonidine. Clonidine decreased IB inhibition in both groups of cats. Mn, Motoneuron. C, Afferent volley was monitored by the CDP. Overall, disynaptic IPSPs (314 trials in 143 cells) evoked by stimulation of knee and ankle extensor group I afferents (Quad, PI, LGS, MG, GS) were significantly decreased by clonidine in shams (30.5\%; $\left.{ }^{*} p<0.05\right)$ and even more significantly in trained cats $\left(61.0 \%\right.$; $\left.{ }^{* * *} p<0.001\right)$. Training enhanced significantly the reduction of IB inhibition after clonidine $\left({ }^{* *} p<0.01\right)$. $d$, Plot of EPSP amplitude versus IPSP amplitude measured from the same cell in shams (filled circles) and trained cats (open circles).

afferents from extensors in sham and trained cats. In Figure 3, the trough of IB inhibition was reduced in the extensor motoneurons after clonidine in both groups of cats (Fig. 3a,b). Overall (Fig. 3c), IB inhibition was decreased by clonidine injection in sham cats (by $30.5 \%$; $p<0.05$ ) and, even more so, in trained cats (by $61.0 \%$; $p<0.001)$. Training was able to enhance the reduction of IB inhibition for responses evoked after clonidine $(p<0.01)$.

Decreases in both monosynaptic excitation and disynaptic inhibition could result from a similar modification in motoneuronal properties (e.g., a decrease in membrane resistance). In Figure $3 d$, we plotted the amplitude of monosynaptic EPSP against the amplitude of disynaptic IPSP measured from the same cell in shams (filled circles) and trained cats (open circles). If both responses were to change together, because of the same motoneuronal modification, one would expect the values from shams to be grouped in the top right corner (i.e., large EPSP and large IPSP together) and the values from trained cats, which are both significantly reduced, to be grouped in the bottom left corner. The considerable scattering of points in this graph suggests on the contrary that these two pathways were modified independently.

The reversal of IB inhibition into excitation was first described in acute spinal cats (Gossard and Hultborn, 1991; Gossard et al., 1994; McCrea et al., 1995). In this system, group I afferents from knee and ankle extensors converge on pathways to produce the excitatory drive to extensor muscles during stance. Here, we investigated the occurrence and amplitude of polysynaptic excitation of extensors in chronic spinal cats after clonidine and train- 

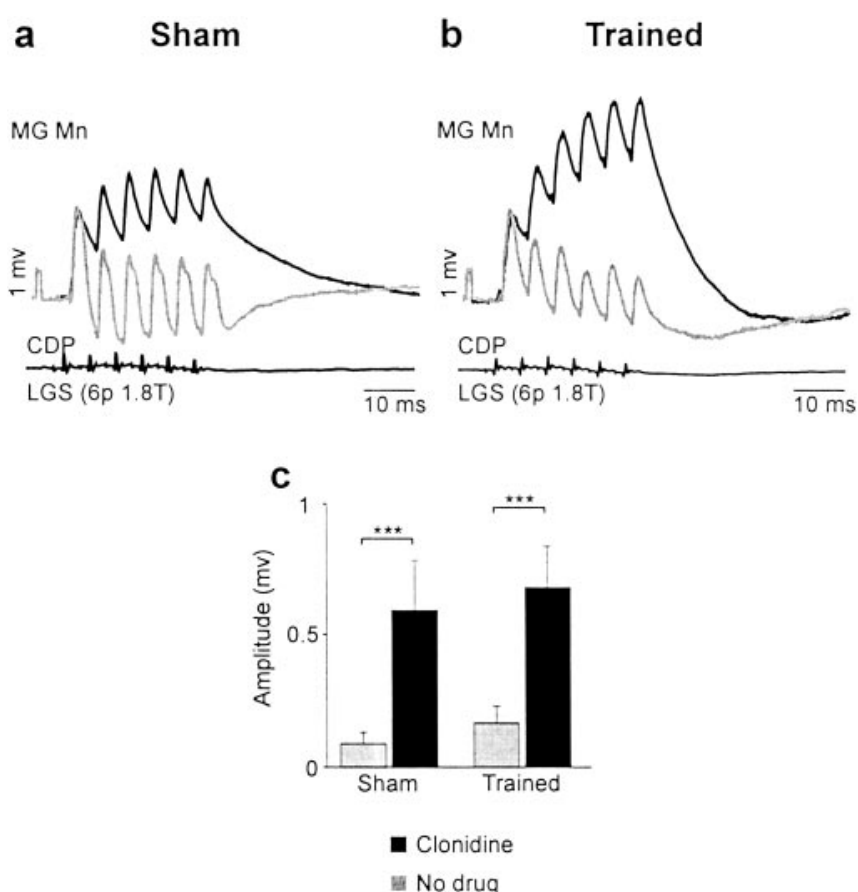

Figure 4. Clonidine increased polysynaptic group I excitation in both groups of cats. $a, b$, EPSPs evoked by stimulation of LGS afferents [6 $\mathrm{p}$ 1.8 T] recorded in MG motoneurons (with similar AHPs) in a sham cat ( $a$ ) and a trained cat $(b)$ before and after clonidine. Here, clonidine reversed IB inhibition ( gray trace) to polysynaptic excitation (black trace) both in sham and trained cats. Mn, Motoneuron. c, Overall, the amplitude of polysynaptic EPSPs (313 trials in 143 cells) evoked by stimulation of knee and ankle extensor group l afferents (Quad, PI, LGS, MG, GS) was increased by clonidine in sham $\left(535.6 \% ;{ }^{* * *} p<0.001\right)$ and in trained $\left(307.8 \%\right.$; ${ }^{* * *} p<$ $0.001)$ cats.

ing. Surprisingly, there were instances of reversals without drugs or locomotion in both sham (8 of 94 trials) and trained ( 9 of 103 trials) cats. This indicates that after 3-4 weeks of spinalization, interneurons in the polysynaptic excitatory pathways recovered some level of excitability. As expected, clonidine injection succeeded in reversing IB inhibition into excitation in motoneurons from both groups of cats, as shown in Figure 4. In shams, the occurrence of reversals was more frequent $(21.5 \% ; p<0.01)$ and its amplitude was greatly increased (from 0.09 to $0.60 \mathrm{mV}$; $535.6 \% ; p<0.001)$ with clonidine. In trained cats, there was a significant increase in amplitude of polysynaptic excitation (from 0.17 to $0.68 \mathrm{mV} ; 307.8 \% ; p<0.001$ ) and a highly significant increase in occurrence $(30.2 \% ; p<0.001)$ attributable to clonidine.

We succeeded in keeping intracellular recordings of four motoneurons while injecting clonidine and had the opportunity to observe changes in responses. In a sham, a Pl cell showed a decrease in IB inhibition (from -7.2 to $-4.1 \mathrm{mV}$ ), and in another sham, an FHL cell showed a reversal from inhibition to excitation (from -2.2 to $1.4 \mathrm{mV}$ ). In a trained cat, an LGS cell showed a decrease in IB inhibition (from -1.6 to $-0.8 \mathrm{mV}$ ) and, in another trained cat, an MG cell showed a reversal (from -2.7 to $1.6 \mathrm{mV}$ ). Similar results were found in the overall population, as reported above. Table 1 gives the mean amplitude of monosynaptic excitation, disynaptic inhibition, and polysynaptic excitation in shams and trained cats before and after clonidine injection.

The long-lasting reflexes evoked by stimulating FRA after administration of L-Dopa in spinal cats are believed to be part of the locomotor circuitry (Jankowska et al., 1967a,b; Schomburg et al., 1998). Moreover, it was shown that group I afferents from extensors and contralateral FRA (coFRA) converge on common interneurons to excite extensors after L-Dopa injection (Gossard et al., 1994). The involvement of the FRA pathways in chronic spinal cats has been questioned (Grillner, 1973; Barbeau et al., 1987). In this study, we found that primarily flexors (16 of 18 cats) and not extensors were excited by coFRA stimulation, with or without clonidine. Similar patterns were observed both in sham cats ( 18 of 24 trials) and trained cats (30 of 38 trials). This strongly suggests that pathways mediating flexion reflexes are deeply reorganized after chronic spinalization.

\section{Training and fictive locomotion}

Before clonidine injection, rhythmic bursts of ENG activity were scarcely evoked by perineal stimulation (Barbeau and Rossignol, 1987; Bélanger et al., 1996) in shams (two of seven cats) (Fig. 5a). Surprisingly, training did not increase significantly the occurrence of fictive locomotor activities (7 of 11 cats) (Fig. 5b). After clonidine, perineal stimulation induced robust and well organized episodes of fictive locomotion in both groups of cats (Fig. $5 c, d)$. As exemplified by reflex reversals, it is now well established that transmission in several sensory pathways is deeply modified during locomotion (Rossignol, 1996). We thus investigated whether fictive stepping disclosed additional effects of training on the transmission of group I pathways (state-dependent changes). We also studied whether training modified the CPGdependent modulation in reflex transmission (phase-dependent changes).

Table 1. The effects of clonidine and training on the mean amplitude of responses in the specified pathway and on occurrence of reversals

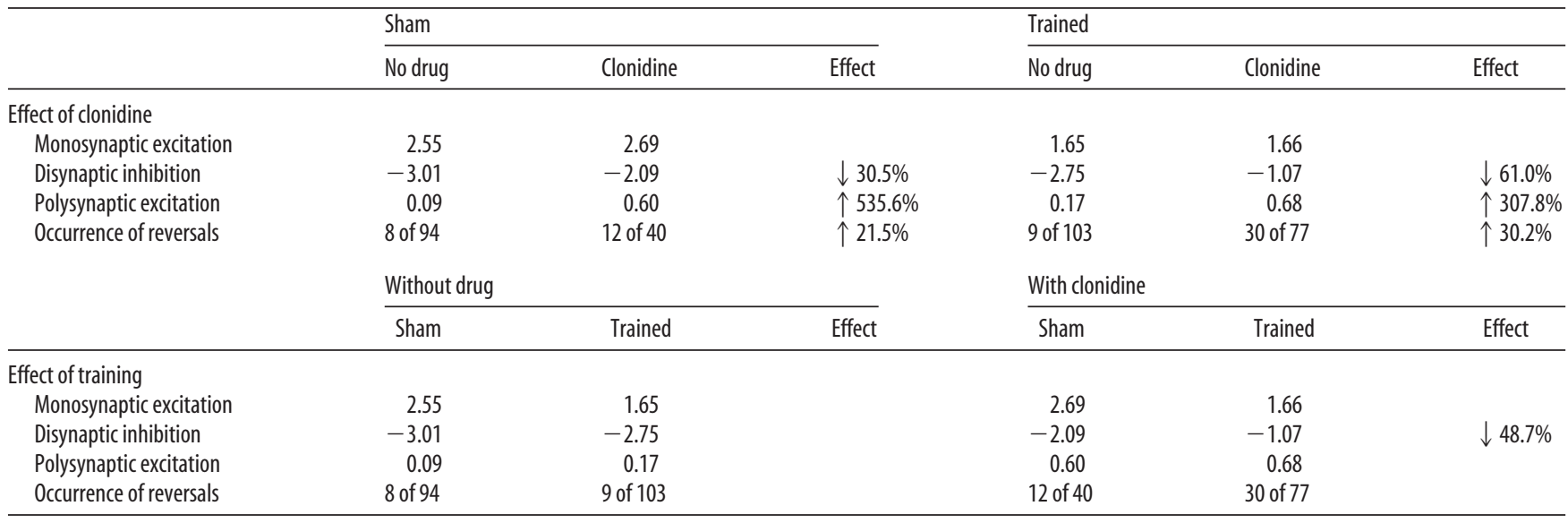

Only statistically significant changes are indicated. 


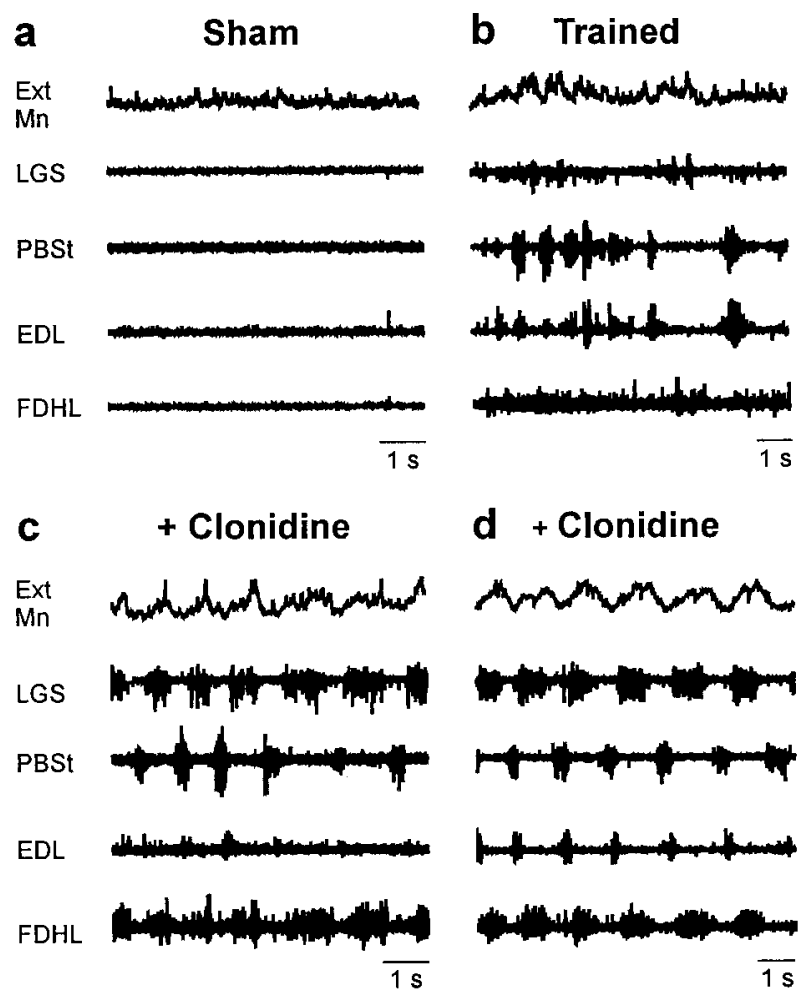

Figure 5. Fictive locomotion can be induced in shams and trained cats. $a, b$, Motoneuronal intracellular potential and ENG activity in flexor and extensor muscle nerves in a sham $(a)$ and a trained $(b)$ cat. Rhythmic bursts of activity evoked by perineal stimulation before clonidine injection were observed in trained cats (7 of 11) and in shams (2 of 7). c, d, After clonidine, perineal stimulation induced robust locomotor episodes in both groups of cats. Ext Mn, Extensor motoneuron.

The amplitude of monosynaptic EPSPs in motoneurons was reported to be decreased during fictive locomotion (by 34\%) induced by mesencephalic stimulation in decerebrate cats because of a tonic level of presynaptic inhibition (Gosgnach et al., 2000). In this study with chronic spinal cats, fictive stepping did not induce a significant decrease in monosynaptic EPSP amplitude compared with rest in both sham (by 31.2\%) and trained (by $29.2 \%$ ) cats. During walking, transmission in the monosynaptic reflex pathway is phasically modulated in the cat (Forssberg and Grillner, 1973; Akazawa et al., 1982; Gossard, 1996; Ménard et al., 1999) and in humans (Capaday and Stein, 1986; Simonsen and Dyhre-Poulsen, 1999), being maximal during stance in extensors when motoneuronal pools are depolarized. Figure 6 illustrates that the phases for maximal amplitude of monosynaptic EPSPs are opposite in a sham and a trained cat. Phase-dependent modulation was found to be significant only in a few trials ( 5 of 29 in 4 of 22 cells) (Gosgnach et al., 2000). Among those, it was found that training significantly modified the pattern of modulation $(p<0.01)$, the maximum amplitude occurring during the depolarized active phase (Fig. $6 c$ ). This very limited sample suggests that training may modify the monosynaptic IA-transmission pathway to extensor motoneurons so that it is maximally transmitting during the extensor (stance) phase.

We also investigated whether fictive stepping disclosed additional effects of training on the transmission of IB inhibitory pathways. It was found that fictive locomotion did not change significantly the amplitude of disynaptic IPSPs compared with rest in both sham ( 48 trials in 27 cells) and trained ( 35 trials in 26 cells) cats. We also assessed the phase-dependent modulation in
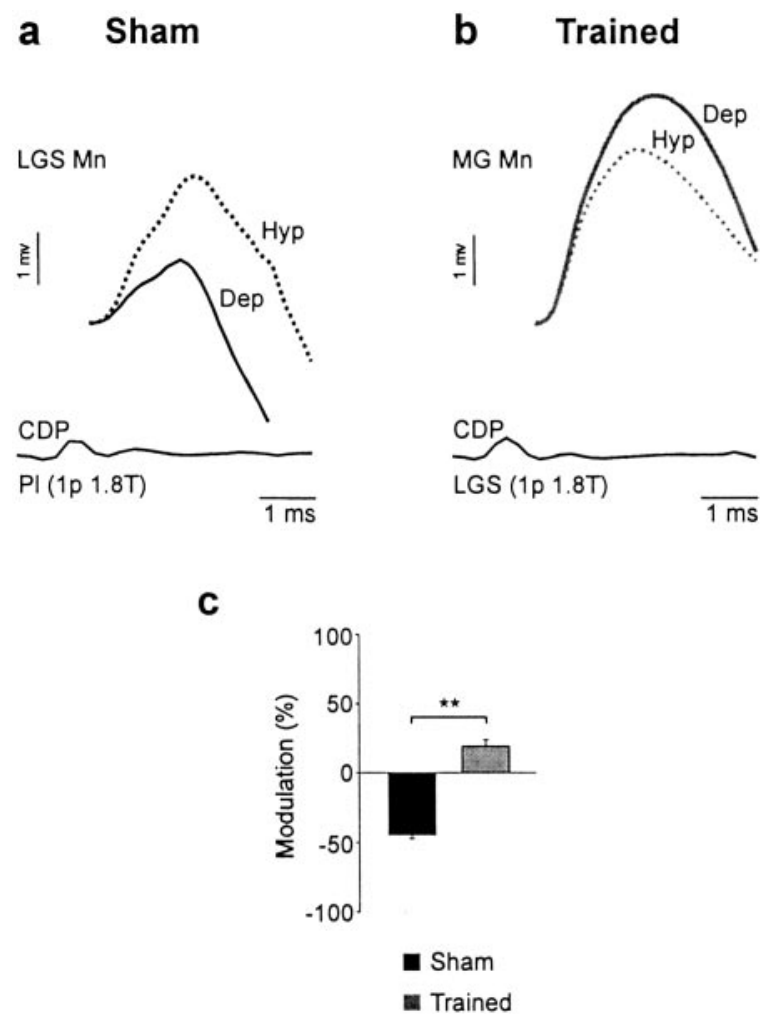

Figure 6. Training could change the pattern of CPG-related modulation of monosynaptic excitation. $a$, The amplitude of monosynaptic EPSPs evoked by PI stimulation [1 p $1.8 \mathrm{~T}$ ] was larger during the hyperpolarized (Hyp) phase in an LGS motoneuron from a sham cat. $b$, The amplitude of monosynaptic EPSPs evoked by LGS stimulation (1 p, 1.8 T) was larger during the depolarized (Dep) phase in an MG motoneuron from a trained cat. Mn, Motoneuron. C, Training modified significantly the pattern of phase-dependent modulation of monosynaptic EPSPs (5 trials in 4 cells; ${ }^{* *} p<0.01$ ) evoked by group I afferents of ankle extensors (PI, MG, LGS), with the maximum amplitude occurring during the hyperpolarized phase in sham cats and during the depolarized phase in trained cats.

IPSP amplitude. Figure 7 illustrates that the amplitude of IPSPs was larger during the depolarized phase in motoneurons in both sham (Fig. 7a) and trained (Fig. 7b) cats. From motoneurons presenting a significant phasic modulation ( 40 of 59 trials in 33 of 41 cells) between depolarized (active) and hyperpolarized phases, it was found that the average depth of modulation was not significantly changed by training (sham, 28.8\%; trained, 29.3\%). Analysis also showed that the IPSP reduction was not related to the amplitude of locomotor depolarization in motoneurons. This suggests that the CPG-related modulation that was similar in both groups probably occurred in IB interneurons.

Compared with rest, the occurrence of reversals from IB inhibition to excitation was more frequent during fictive locomotion in shams $(25.1 \% ; p<0.001)$ but not in trained cats $(11.7 \%$; not significant). Also, the amplitude of responses was much increased during fictive stepping in shams ( 48 trials, by $225.5 \%$; $p<0.05$ ), whereas it was unchanged in trained cats (36 trials). We also assessed its phase-dependent modulation. For example, in Figure 8 , the amplitude of polysynaptic EPSPs was increased during the depolarized phase in the motoneuron from a sham (Fig. 8a), whereas it was decreased during that same phase in a motoneuron from a trained cat (Fig. $8 b$ ). From motoneurons presenting a significant phasic modulation ( 19 of 29 trials in 15 of 21 cells), it was found that the average depth of modulation was not significantly changed by training. However, the polysynaptic excitation was larger (by $8.1 \%$ ) during the depolarized phase in sham cats, 
a

Sham

b

Trained
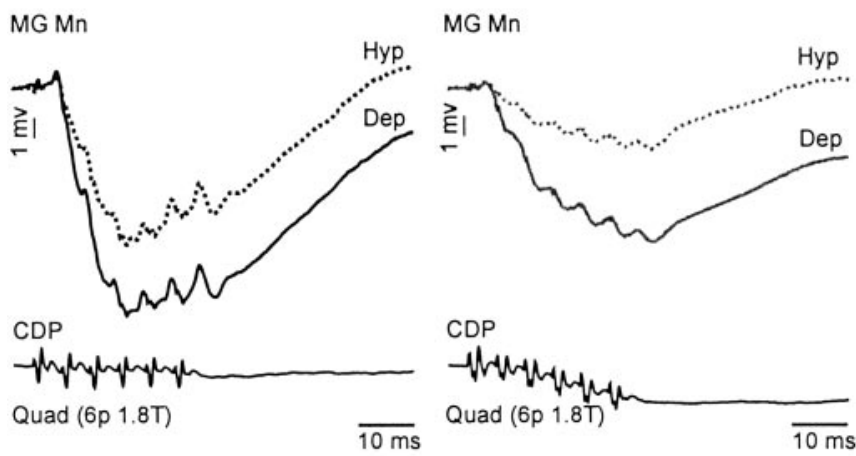

C

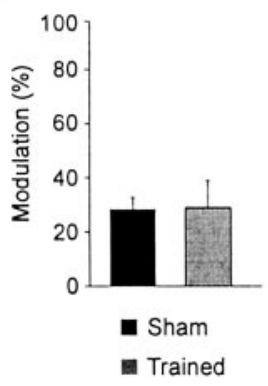

Figure 7. Training did not change the pattern of CPG-related modulation of IB inhibition. $a$, $b$, IPSPs evoked by Quad $(6 p, 1.8 \mathrm{~T})$ in MG motoneurons during fictive locomotion in a sham (a) and a trained $(b)$ cat. The amplitude of IPSPs (trough) was increased during the depolarized (dep) phase in the sham (black trace) and the trained (gray trace) cat. Mn, Motoneuron. c, The depth of modulation in IPSPs (40 trials in 33 cells) was not significantly changed by training. Hyp, hyperpolarized.

whereas it was decreased (by 19.3\%) during that same phase in trained cats (Fig. $8 c$ ). The fact that, in trained cats, the amplitude of polysynaptic excitation is smaller during fictive stepping compared with rest and smaller during the depolarized phase may be attributable to the occlusion of this pathway caused by its recruitment by the CPG to produce extensor activities (Gossard and Hultborn, 1991; Gossard et al., 1994). This was evaluated by comparing in both groups of cats the linear regressions relating the amplitude of polysynaptic excitation and the amplitude of locomotor bursts of activity of the parent extensor nerve. In shams, the amplitude of polysynaptic excitation was growing with increasing ENG-burst amplitude (upward slope), whereas in trained cats, it decreased with increasing ENG bursts (downward slope), and this difference was significant $(p<0.03)$.

\section{Discussion}

Acute experimentation in curarized animals is advantageous to investigate transmission of sensory pathways because it allows stable intracellular recordings, and responses can be solely attributed to the operation of central networks. The effects of training or clonidine observed in this study can then be attributed to changes occurring in spinal pathways and not to an alteration in peripheral sensory events or muscle fibers. There is now growing evidence that reflex pathways are not "hard-wired" (Forssberg and Svartengren, 1983), and that they can display a certain level of plasticity in response to central or peripheral lesions or operant conditioning (Mendell, 1984; Durkovic, 1996; Wolpaw, 1997; Wolpaw and Tennissen, 2001). The recovery of stepping with treadmill training has been attributed solely to plasticity of the a

Sham

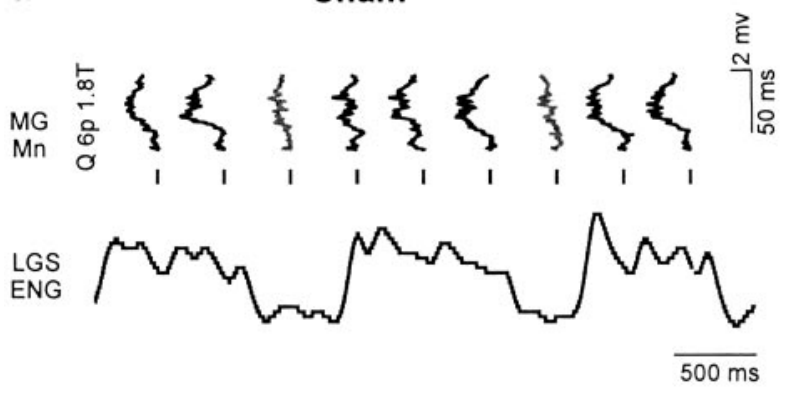

b

Trained

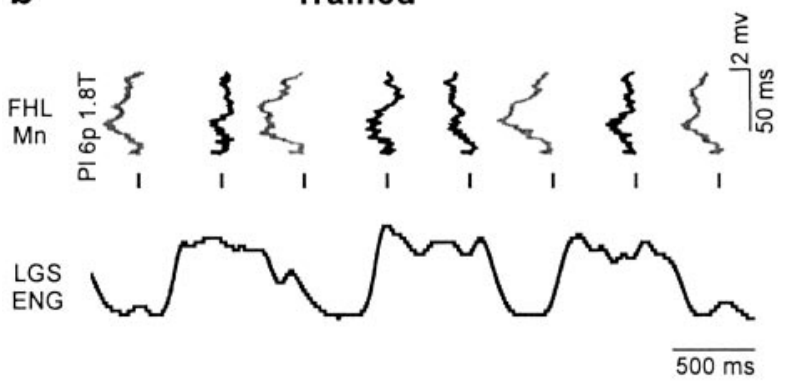

C

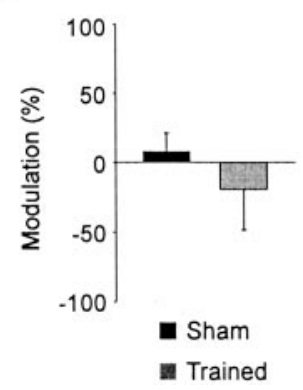

Figure 8. Different patterns of CPG-related modulation of polysynaptic excitation. $a$, EPSPs recorded in an $M G$ motoneuron (tilted $90^{\circ}$ ) in a sham were evoked by Quad stimuli $[6 \mathrm{p} 1.8 \mathrm{~T}]$ at different moments in the step cycle illustrated by the rectified and filtered ENG activity of the LGS nerve. The amplitude of polysynaptic EPSPs was maximal ( gray trace) when occurring during the active period of LGS (i.e., during the extension phase). $b$, The amplitude of polysynaptic EPSPs evoked by PI stimulation and recorded in an FHL motoneuron (tilted $90^{\circ}$ ) from a trained cat $(6 \mathrm{p}, 1.8 \mathrm{~T})$ was minimal (black trace) during the extension phase when LGS was maximally active. Mn, Motoneuron. c, Overall, the pattern of phase-dependent modulation of polysynaptic EPSPs (19 trials in 15 cells) tended to be opposite in shams and trained cats, but this difference was not statistically significant.

CPG (Lovely et al., 1986; Rossignol, 1996; Harkema, 2001). This study is the first to report that recovery of locomotion may also involve changes in several reflex pathways. Plastic changes in a reflex arc can occur in motoneurons, interneurons, or primary afferents. Our results showed that stimulation of the same group I afferents could elicit opposite response patterns in two different pathways (monosynaptic and polysynaptic), one being increased and the other decreased in amplitude, in the same motoneuron. Also, decreases in monosynaptic and disynaptic responses did not appear to covary in the same motoneuron. Additionally, clonidine injection significantly modified transmission in disynaptic pathways without affecting monosynaptic transmission. Moreover, AHP duration, which varies systematically with input resistance and membrane time constant (Gustafsson and Pinter, 1984), was found not to be modified by 1 month of training (data not shown). Therefore, premotoneuronal mechanisms can most easily explain our response patterns. Finally, there is an unknown 
contribution and plastic modification of recurrent inhibition in our recordings. However, IB inhibition and its reduction caused by training were observed between motoneurons (e.g., Quad) and group I fibers from muscle nerves (e.g., Pl) known to lack recurrent inhibitory connections (Baldissera et al., 1981). We thus believe that plasticity induced by training in load pathways was occurring primarily in interneurons of the group I pathways to extensors and interneurons of presynaptic inhibition.

The first finding of this work is that training decreases monosynaptic excitation by $36 \%$. This was apparent when we pooled all amplitude values because of the lack of significant effect of clonidine on this transmission. In the few cells in which it was possible to test, the phase-dependent modulation showed a maximum monosynaptic transmission occurring during the extensor phase in trained cats in which it could help the excitation of motoneurons. Intrathecal injection of clonidine also failed to change the H-reflex in incomplete paraplegic subjects (RémyNéris et al., 1999). Also, treadmill training decreased and improved the gating of IA reflexes in spinal-cord-injured humans compared with normal subjects (Trimble et al., 1998). Transmission in this pathway can be changed by presynaptic inhibition and/or motoneuronal properties. As explained above, postsynaptic changes alone cannot easily explain all of the response patterns observed in this work. We thus believe that training may have increased the level of presynaptic inhibition in IA terminals ending in the ventral horn. Such an increase was inferred to explain a general (non-muscle-specific) tonic decrease in IA-EPSPs (by $34 \%$ ) in a majority of hindlimb motoneurons during fictive locomotion evoked by mesencephalic stimulation in the cat (Gosgnach et al., 2000). We thus suggest that training could help reduce spasticity by decreasing IA transmission and improve phase-dependent modulation of the stretch reflexes during stepping.

Another main finding from this work is that the decrease in IB inhibition after clonidine is enhanced by training. A normalization of inhibitory systems in the spinal cord may be of prime importance in recovering stepping (Robinson and Goldberger, 1986; De Leon et al., 1999). For example, it was recently described that the number of cells stained for GAD67 mRNA was specifically decreased by step training in laminas V and VI (in which IB interneurons are located) in spinal cats (Tillakaratne et al., 2002). Note that during reflex reversal, the disappearance of disynaptic inhibition precedes the appearance of polysynaptic excitation (Gossard et al., 1994; McCrea et al., 1995). We thus interpret the observed reduction of IB inhibition as a first step toward reversals. The results also showed that clonidine increased more significantly the occurrence of polysynaptic excitation in trained cats than in shams. However, it was surprising not to see more effects of training on the amplitude of polysynaptic excitation. Perhaps smaller doses of clonidine would have revealed more differences. Indeed, the dose used $(500 \mu \mathrm{g} / \mathrm{kg})$ was determined from previous reports on acute spinal cats and is possibly more than sufficient to evoke reflex reversals in all spinal cats.

Fictive locomotion did not reveal additional training-related changes in IB inhibition amplitude or phase-dependent modulation patterns. However, it showed that the minimal amplitude in polysynaptic excitation occurred during the extensor phase when the locomotor excitation is maximal in trained cats. We interpret this pattern as being attributable to the occlusion of the pathways by the action of the CPG during the extensor phase as it was proposed in the acute spinal cat (Gossard et al., 1994). We interpret this as being another step toward the establishment of locomotor-related polysynaptic excitatory pathways to extensors caused by training. The same reasoning may help explain why the occurrence and amplitude of polysynaptic excitation in shams were increased during fictive stepping. If locomotor circuitry is not as well established in shams as in trained cats, there is less occlusion in these pathways and the segmental responses become more apparent.

In the decerebrate cat walking on a treadmill, it was estimated that up to $50 \%$ of the force generated during the stance phase was caused by muscle reflexes (Hiebert and Pearson, 1999; Stein et al., 2000). We may presume that the isolated spinal cord would depend even more on sensory feedback to generate force during stepping. Although modest, the reported plastic changes indicate that after spinal cord injury, load pathways would have a larger contribution in the control of stance if trained regularly and together with pharmacological intervention. Our results support previous reports that load receptors may contribute to the activation of leg extensors during walking in humans (Ghori and Luckwill, 1985; Dietz et al., 1992; Stephens and Yang, 1999; Sinkjaer et al., 2000; Stein et al., 2000). For example, it was proposed that afferent inputs from receptors signaling contact forces during the stance phase are essential for the activation of spinal locomotor centers in SCI subjects (Harkema et al., 1997). Moreover, the improvement in treadmill and overground locomotor patterns was attributed to the repetitive alternating-limb loading using body-weight support (Wernig et al., 1998). Whether treadmill training or repetitive loading revived the previous (prespinalization) CPG or whether it set up a new locomotor circuitry is still debatable. Our results indicate clearly that some pathways involved in locomotion in the acute spinal cat, namely the FRA networks (Jankowska et al., 1967a,b), are reorganized after chronic spinalization (Barbeau et al., 1987). Moreover, fictive stepping sometimes occurred without concomitant appearance of group I polysynaptic excitation in some extensor motoneurons, which was not seen in the acute cat injected with L-Dopa (Gossard et al., 1994). Thus, as proposed previously (Hodgson et al., 1994; De Leon et al., 1999), our results support the idea that the isolated spinal cord "learned" how to walk by establishing new locomotor pathways.

\section{References}

Akazawa K, Aldridge JW, Steeves JD, Stein RB (1982) Modulation of stretch reflexes during locomotion in the mesencephalic cat. J Physiol (Lond) 329:553-567.

Baldissera F, Hultborn H, Illert M (1981) Integration in spinal neuronal systems. In: Handbook of physiology. The nervous system, Vol II (Brookhart JM, Mountcastle VB, eds), pp 509-595. Bethesda, MD: American Physiological Society.

Barbeau H, Rossignol S (1987) Recovery of locomotion after chronic spinalization in the adult cat. Brain Res 412:84-95.

Barbeau H, Rossignol S (1991) Initiation and modulation of the locomotor pattern in the adult chronic spinal cat by noradrenergic, serotonergic and dopaminergic drugs. Brain Res 546:250-260.

Barbeau H, Julien C, Rossignol S (1987) The effects of clonidine and yohimbine on locomotion and cutaneous reflexes in the adult chronic spinal cat. Brain Res 437:83-96.

Bélanger M, Drew T, Provencher J, Rossignol S (1996) A comparison of treadmill locomotion in adult cats before and after spinal transection. J Neurophysiol 76:471-491.

Capaday C, Stein RB (1986) Amplitude modulation of the soleus H-reflex in the human during walking and standing. Neural control of stereotypic limb movements. J Neurosci 6:1308-1313.

Chau C, Barbeau H, Rossignol S (1998) Early locomotor training with clonidine in spinal cats. J Neurophysiol 79:392-409.

De Leon RD, Hodgson JA, Roy RR, Edgerton VR (1998) Locomotor capacity attributable to step training versus spontaneous recovery after spinalization in adult cats. J Neurophysiol 79:1329-1340. 
De Leon RD, Hodgson JA, Roy RR, Edgerton VR (1999) Retention of hindlimb stepping ability in adult spinal cats after the cessation of step training. J Neurophysiol 81:85-94.

Dietz V, Gollhofer A, Kleiber M, Trippel M (1992) Regulation of bipedal stance: dependency on "load" receptors. Exp Brain Res 89:229-231.

Durkovic RG (1996) The spinal cord: a simplified system for the study of neural mechanisms of mammalian learning and memory. In: Development and plasticity of the mammalian cord (Goldberger M, Gorio A, Murray M, eds), pp 149-162. New York: Springer.

Duysens J, Clarac F, Cruse H (2000) Load-regulating mechanisms in gait and posture: comparative aspects. Physiol Rev 80:83-133.

Forssberg H, Grillner S (1973) The locomotion of the acute spinal cat injected with clonidine i.v. Brain Res 50:184-186.

Forssberg H, Svartengren G (1983) Hardwired locomotor network in cat revealed by a retained motor pattern to gastrocnemius after muscle transposition. Neurosci Lett 41:283-288.

Fung J, Stewart JE, Barbeau H (1990) The combined effects of clonidine and cyproheptadine with interactive training on the modulation of locomotion in spinal cord injured subjects. J Neurol Sci 100:85-93.

Ghori GM, Luckwill RG (1985) Responses of the lower limb to load carrying in walking man. Eur J Appl Physiol Occup Physiol 54:145-150.

Gosgnach S, Quevedo J, Fedirchuk B, McCrea DA (2000) Depression of group Ia monosynaptic EPSPs in cat hindlimb motoneurons during fictive locomotion. J Physiol (Lond) 526:639-652.

Gossard J-P (1996) Control of transmission in muscle group IA afferents during fictive locomotion in the cat. J Neurophysiol 76:4104-4112.

Gossard J-P, Hultborn H (1991) The organization of the spinal rhythm generation in locomotion. In: Plasticity of motoneuronal connections (Wernig A, ed), pp 385-404. Amsterdam: Elsevier.

Gossard J-P, Brownstone RM, Barajon I, Hultborn H (1994) Transmission in a locomotor-related group Ib pathway from hindlimb extensor muscles in the cat. Exp Brain Res 98:213-228.

Grillner S (1973) Locomotion in the spinal cat. In: Control of posture and locomotion. Advances in Behavioral Biology, Vol 7 (Stein RB, Pearson KG, Smith RS, Redford JB, eds), pp 515-535. New York: Plenum.

Gustafsson B, Pinter MJ (1984) Relations among passive electrical properties of lumbar $\alpha$-motoneurones of the cat. J Physiol (Lond) 356:401-431.

Harkema SJ (2001) Neural plasticity after human spinal cord injury: application of locomotor training to the rehabilitation of walking. The Neuroscientist 7:455-468.

Harkema SJ, Hurley SL, Patel UK, Requejo PS, Dobkin BH, Edgerton VR (1997) Human lumbosacral spinal cord interprets loading during stepping. J Neurophysiol 77:797-811.

Hiebert GW, Pearson KG (1999) Contribution of sensory feedback to the generation of extensor activity during walking in the decerebrate cat. J Neurophysiol 81:758-770.

Hodgson JA, Roy RR, De Leon R, Dobkin B, Edgerton VR (1994) Can the mammalian lumbar spinal cord learn a motor task? Med Sci Sports Exerc 26:1491-1497.

Jankowska E (1992) Interneuronal relay in spinal pathways from proprioceptors. Prog Neurobiol 38:335-378.

Jankowska E, McCrea DA (1983) Shared reflex pathways from Ib tendon organ afferents and Ia muscle spindle afferents in the cat. J Physiol (Lond) 338:99-111.

Jankowska E, Jukes MG, Lund S, Lundberg A (1967a) The effect of DOPA on the spinal cord. 5. Reciprocal organization of pathways transmitting excitatory action to alpha motoneurones of flexors and extensors. Acta Physiol Scand 70:369-388.

Jankowska E, Jukes MG, Lund S, Lundberg A (1967b) The effects of DOPA on the spinal cord. 6. Half centre organization of interneurones transmitting effects from the flexor reflex afferents. Acta Physiol Scand 70:389-402.
Leblond H, Ménard A, Gossard J-P (2000) Bulbospinal control of spinal cord pathways generating locomotor extensor activities in the cat. J Physiol (Lond) 525:225-240.

Lovely RG, Gregor RJ, Roy RR, Edgerton VR (1986) Effects of training on the recovery of full-weight-bearing stepping in the adult spinal cat. Exp Neurol 92:421-435.

McCrea DA, Shefchyk SJ, Stephens MJ, Pearson KG (1995) Disynaptic group I excitation of synergist ankle extensor motoneurones during fictive locomotion in the cat. J Physiol (Lond) 487:527-539.

Ménard A, Leblond H, Gossard J-P (1999) The modulation of presynaptic inhibition in single muscle primary afferents during fictive locomotion in the cat. J Neurosci 19:391-400.

Mendell LM (1984) Modifiability of spinal synapses. Physiol Rev 64:260-324.

Prochazka A (1996) Proprioceptive feedback and movement regulation. In: Handbook of physiology, section 12. Exercise: regulation and integration of multiple systems (Rowell LB, Sheperd JT, eds), pp 89-127. New York: American Physiological Society.

Rémy-Néris O, Barbeau H, Daniel O, Boiteau F, Bussel B (1999) Effects of intrathecal clonidine injection on spinal reflexes and human locomotion in incomplete paraplegic subjects. Exp Brain Res 129:433-440.

Robinson GA, Goldberger ME (1986) The development and recovery of motor function in spinal cats. II. Pharmacological enhancement of recovery. Exp Brain Res 62:387-400.

Rossignol S (1996) Neural control of stereotypic limb movements. In: Handbook of physiology, section 12. Exercise: regulation and integration of multiple systems (Rowell LB, Sheperd JT, eds), pp 173-216. New York: American Physiological Society.

Schomburg ED, Petersen N, Barajon I, Hultborn H (1998) Flexor reflex afferents reset the step cycle during fictive locomotion in the cat. Exp Brain Res 122:339-350.

Simonsen EB, Dyhre-Poulsen P (1999) Amplitude of the human soleus H reflex during walking and running. J Physiol (Lond) 515:929-939.

Sinkjaer T, Andersen JB, Ladouceur M, Christensen LO, Nielsen JB (2000) Major role for sensory feedback in soleus EMG activity in the stance phase of walking in man. J Physiol (Lond) 523:817-827.

Stein RB, Misiaszek JE, Pearson KG (2000) Functional role of muscle reflexes for force generation in the decerebrate walking cat. J Physiol (Lond) 525:781-791.

Stephens MJ, Yang JF (1996) Short latency, non-reciprocal group I inhibition is reduced during walking in humans. Brain Res 743:24-31.

Stephens MJ, Yang JF (1999) Loading during the stance phase of walking in humans increases the extensor EMG amplitude but does not change the duration of the step cycle. Exp Brain Res 124:363-370.

Tillakaratne N, De Leon R, Hoang TX, Roy RR, Edgerton VR, Tobin AJ (2002) Use-dependant modulation of inhibitory capacity in the feline lumbar spinal cord. J Neurosci 22:3130-3143.

Trimble MH, Kukulka CG, Behrman AL (1998) The effect of treadmill gait training on low-frequency depression of the soleus H-reflex: comparison of a spinal cord injured man to normal subjects. Neurosci Lett 246:186-188.

Wernig A, Muller S, Nanassy A, Cagol E (1995) Laufband therapy based on "rules of spinal locomotion" is effective in spinal cord injured persons. Eur J Neurosci 7:823-829.

Wernig A, Nanassy A, Muller S (1998) Maintenance of locomotor abilities following Laufband (treadmill) therapy in para- and tetraplegic persons: follow-up studies. Spinal Cord 36:744-749.

Wolpaw JR (1997) The complex structure of a simple memory. Trends Neurosci 20:588-594.

Wolpaw JR, Tennissen AM (2001) Activity-dependent spinal cord plasticity in health and disease. Annu Rev Neurosci 24:807-843. 